\title{
HSS DEPOSITION BY PTA - FEASIBILITY AND PROPERTIES
}

\author{
Pavel Rohan ${ }^{1}$, Tomáš Kramár ${ }^{1}$, Jaroslav Petr² \\ 1 Department of Manufacturing Technology, Faculty of Mechanical Engineering, Czech Technical University in \\ Prague, Technická 4, Praha 6, Czech Republic, e-mail: pavel.rohan@fs.cvut.cz \\ 2 Department of Materials Engineering, Faculty of Mechanical Engineering, Czech Technical University in \\ Prague, Karlovo náměstí 13, Praha 2, Czech Republic
}

Received: 2015.12.15

Accepted: 2016.02.01

Published: 2016.03.01

\begin{abstract}
High speed steels (HSS) as iron alloys reinforced by carbides of tungsten, chromium, vanadium and/or cobalt are known for more than 100 years. HSS is commonly used for cutting tools fabrication because of their high hardness, ductility, and strength and temperature resistance. Recently many different kinds of thin layers are often deposited on HSS tools in order to increase their lifetime. HSS are produced by conventional metallurgical methods and the tools are hardened by quenching and tempering. Recently, large part of HSS tools are produced by powder metallurgy (i.e. HIPhot isostatic pressing). There are also some studies about thermal spraying of HSS but there is no evidence about Plasma Transfer Arc cladding of HSS. Two powders of HSS 23, resp. HSS30 grade were selected and deposited by Plasma Transfer Arc (PTA) and pulsed PTA on to mild steel substrate. In order to find the ability of thick layer forming, four layers cladding were used. To minimize heat input the influence of $76 \mathrm{~Hz}$ pulsation was also studied. Vickers hardness was measured on cross section and metallography of coatings was done. It was found that with selected parameters thick layer of HSS can be deposited. Pulsation increases the hardness of coatings in comparison with layers produced by direct current PTA. PTA and pulsed PTA methods of HSS parts fabrication can be used for both manufacturing and reparation of cutting tools and also for 3D additive manufacturing process.
\end{abstract}

Keywords: high speed steel, plasma transfer arc cladding, pulsed PTA, multilayer thick coatings, hardness.

\section{INTRODUCTION}

Plasma Transferred Arc (PTA) weld surfacing attracts attention by improving the wear, corrosion and heat resistance of material surface, due to its high deposition rate and lower heat input [1]. PTA overlay welding consists of feeding melting powder into transferred plasma jet. Melted filler material creates a melting pool on the substrate surface and after crystallization creates a welding bead (deposit, coating). PTA hardfacing is widely used also thanks to low dilution of deposited coating with base material. Continuous current is traditionally used with an amperage from 40 to 250 Amps, however, pulsed current usage is rarely reported [2, 3]. Pulsed-PTA is characterized by lower heat input and consequently higher cooling rate of deposit. The other main parameters can be distinguished to the following groups: torch trajectory characteristics (torch speed, waving, nozzle to work piece distance), torch characteristics (amperage, pulse - frequency, low/high current amperage, gases) and feeding characteristics (rate, gas). The influence of the PTA parameters on cladding process is reported in $[4,5]$.

High speed steels (HSS) started their history one hundred years ago by development of first alloy based on tungsten. Up to now, many other alloys were developed and put in process. High speed steels are so named primarily because of their ability to machine materials at high cutting speeds. They are complex iron-base alloys of 
carbon, chromium, vanadium, molybdenum, or tungsten, or combinations thereof, and in some cases substantial amounts of cobalt [6]. Cobalt is added in order to maintain hot hardness, thus to increase the cutting efficiency when high tool temperatures are attained during the cutting operation [6]. Cobalt contributes to hot hardness by considerably hardening ferrite through a solid solution [7]. Cobalt influence on alloy properties, such as hardening, high temperatures applications and in high temperature of magnetic materials [8]. Generally, HSS are divided into the categories following the most important alloying elements such as Mo and W. Presently, there are more than 150 types of HSS denominated by AISI and other national standards. Carbides can be added into a composite based on HSS, in order to improve hardness and wear resistance of HSS tungsten [9].

A number of methods is now used to make components from HSS. Apart of conventional casting, powder metallurgy, Ospray process, spraying and laser sintering or cladding take place [10-16]. The usage of PTA and pulse-PTA method for preparing HSS components and coatings was studied rarely [17].

\section{EXPERIMENTAL}

Two alloys based on high speed steel composition in a form of powder with grain size 63-180 $\mu \mathrm{m}$ (Figures 1, 2) (DEW, Germany) were deposited on the mild steel plate. Denomination of alloys

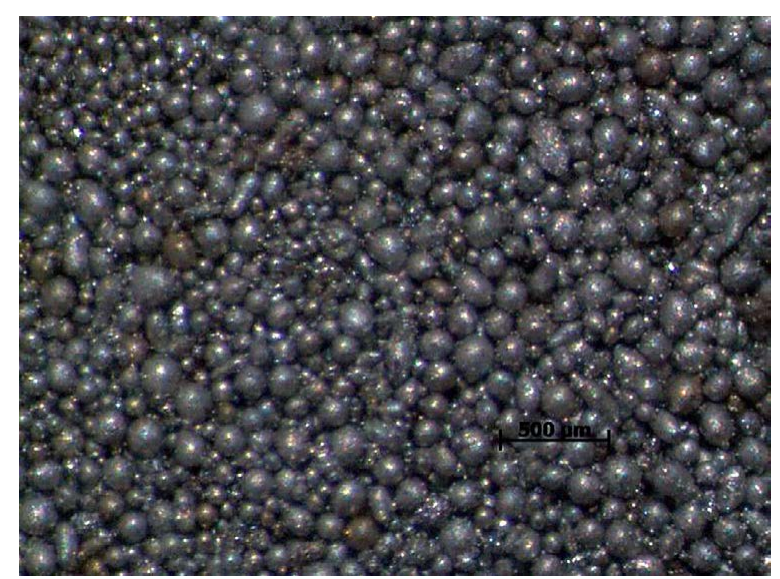

Fig. 1. HSS 23 feedstock powder is HSS 23 and HSS 30 (heat no. 255844, resp. 256093) and chemical composition is in table (Table 1). The only difference between chemical compositions of these two alloys is the content of cobalt (0, resp. $8.2 \% \mathrm{wt}$ ). AISI denomination of HSS23 is M3:2.

Deposits were cladded by the Plasma surfacing automate PPC 250 R6 (KSK, s.r.o, Czech Rep.) destined for surfacing of rotary parts from face or onto the circuit by a PTA method. This automate has a positioning system with 6 controlled axes and programming by a method "demonstrate and execute" or in a dialog. Two powder feeders allow using both single powder and a mixture of the two. Feeding, shielding and plasma gas can be supplied independently. Industrial argon 4.8 was used for all three purposes.

Temperature of interpass was controlled by a thermocouple in the middle of deposit length. Thermocouples were welded $3 \mathrm{~mm}$ alongside the deposits. First, the layer was deposited on substrate at room temperature and interpass temperature was maintained at $400{ }^{\circ} \mathrm{C}$. Grinded mild steel S355 of $15 \mathrm{~mm}$ thickness was used as a substrate.

Deposits were made by 4 layers of $25 \mathrm{~mm}$ width and $85 \mathrm{~mm}$ length by both PTA and pulsed PTA processes. The amperage of 140A, resp. 210/77A for pulse-PTA was used, oscillation of $25 \mathrm{~mm}$ with speed of $6 \mathrm{~mm} \cdot \mathrm{s}^{-1}$ and speed of torch was $0.3 \mathrm{~mm} \cdot \mathrm{s}^{-1}$.

Metallographic evaluation was performed by both light and electron microscopes. Light metallographic microscope Zeiss (Observer.D1m) was

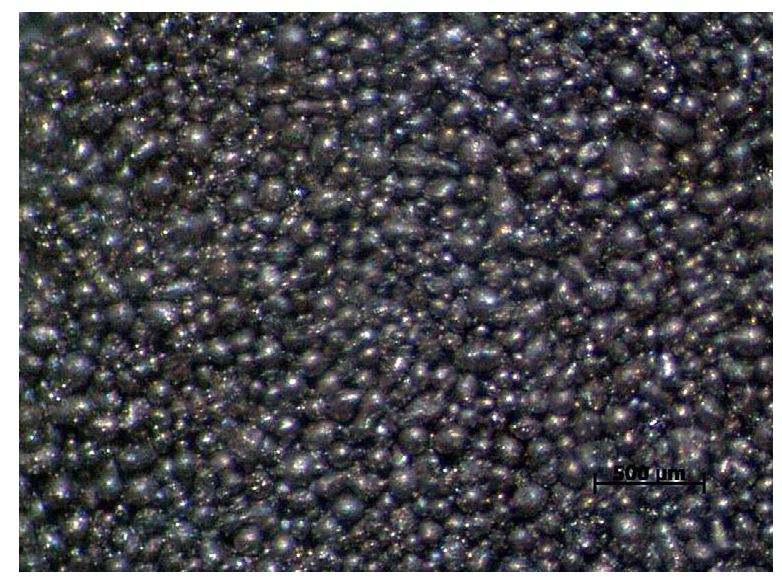

Fig. 1. HSS 30 feedstock powder

Table 1. Chemical composition of deposited HSS (wt \%)

\begin{tabular}{|c|c|c|c|c|c|c|c|}
\hline Alloy & Mo & W & Cr & V & Mn & Fe & Co \\
\hline HSS 23 & 5.19 & 6.07 & 4.05 & 3.18 & 0.20 & bal & 0.0 \\
\hline HSS 30 & 4.81 & 6.22 & 4.15 & 3.06 & 0.27 & bal & 8.3 \\
\hline
\end{tabular}


used and electron microscope JEOL JSM 7200F with LABe (Low Angle Backscatter) sensor. The area of interest was placed at $1 \mathrm{~mm}$ under free surface of the deposits.

Vickers hardness was measured by Buehler micro hardness tester.

\section{RESULTS AND DISCUSSION}

The cross sections of the four cladded deposits presented no cracks in their structure. The thickness of the deposits varied from 12 to $13.5 \mathrm{~mm}$. The macroscopic view does not show structure inhomogeneity and each overlay welding layer is difficult to distinguish. Penetration of deposits in to the base material is less than $1 \mathrm{~mm}$. The deposits are metallurgically bonded to the base material and no porosity neither cracks were detected on deposit boundary.

Microstructure of deposited HSS contains carbides of Vanadium, Molybdenum and Tungsten (Figure 3) in an iron matrix. $\mathrm{Cr}$ and $\mathrm{Co}$ are uniformly dissolute in Iron matrix. Single chromium carbides were not detected and cobalt is present as solid solution in iron. The matrix grain size is uniformly distributed without any crystallization direction preference. The carbides are located on the grain boundaries. Vanadium carbides are present in small rounded form in contrast to molybdenum, resp. tungsten carbides which forms a thin lamellae shape $[14,16,17,18]$. The same shape of carbides was found in HSS 23, resp. HSS 30 deposits as shown on electron microscope maps (Figure 4). Molybdenum and tungsten are difficult to distinguish by EDS sensor, so lamellae shaped carbides can be molybdenum as well as tungsten.

Hardness of deposits was measured on the line parallel with free surface of the deposits and on the line perpendicular to the boundary between the weld and the base material (Figure 5). Hardness measured $1 \mathrm{~mm}$ under the free surface shows the influence of plasma current pulsation (Figure 6). Both HSS's deposit types are harder after the pulse-PTA deposition. This phenomenon can be explained by lower heat input in comparison with conventional PTA method and consequently, by higher cooling rate of the deposits during cladding. The deposit of HSS 30 made by pulse-PTA method is the hardest, because cobalt in solid solution with iron reinforce

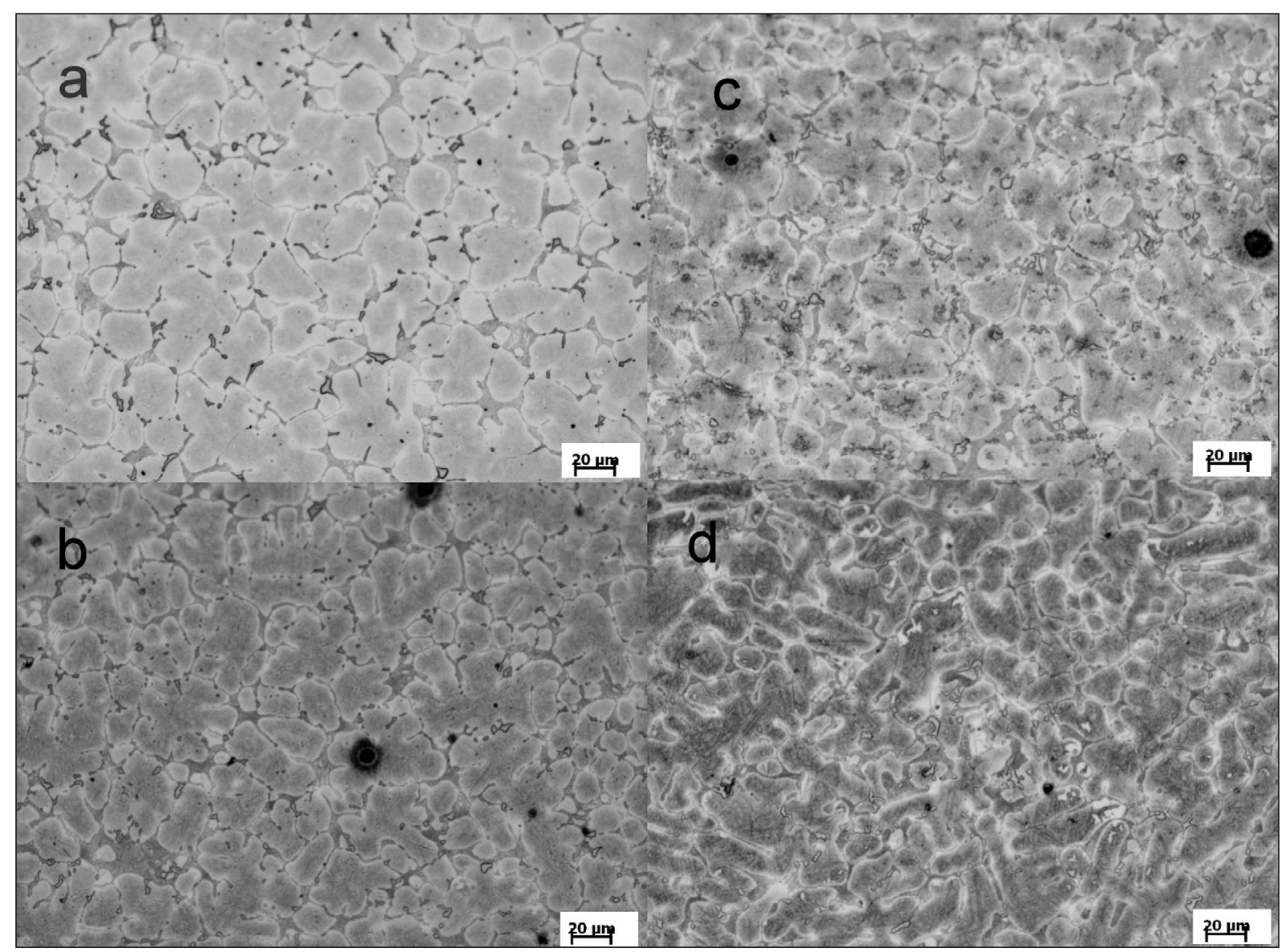

Fig. 3. Microstructure of HSS 23 - a, b and HSS30 - c, d. Conventional PTA - a, c; pulse-PTA - b, d; 200× 


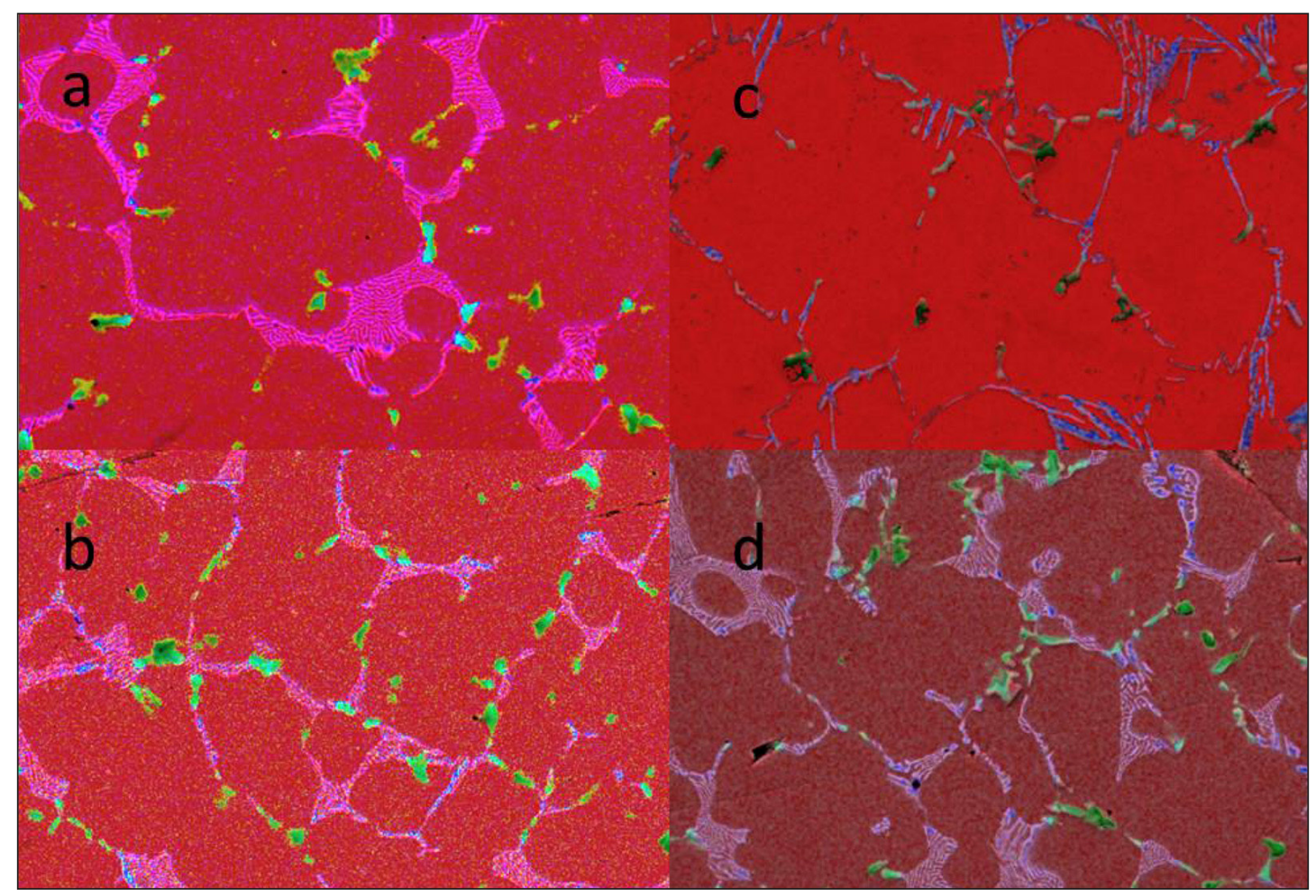

Fig. 4. EDS map - red-iron, cobalt, green-vanadium, violet/blue-tungsten, molybdenum. HSS 23 - a, b and HSS 30 - c, d. Conventional PTA - a, c; pulse-PTA - b, d.

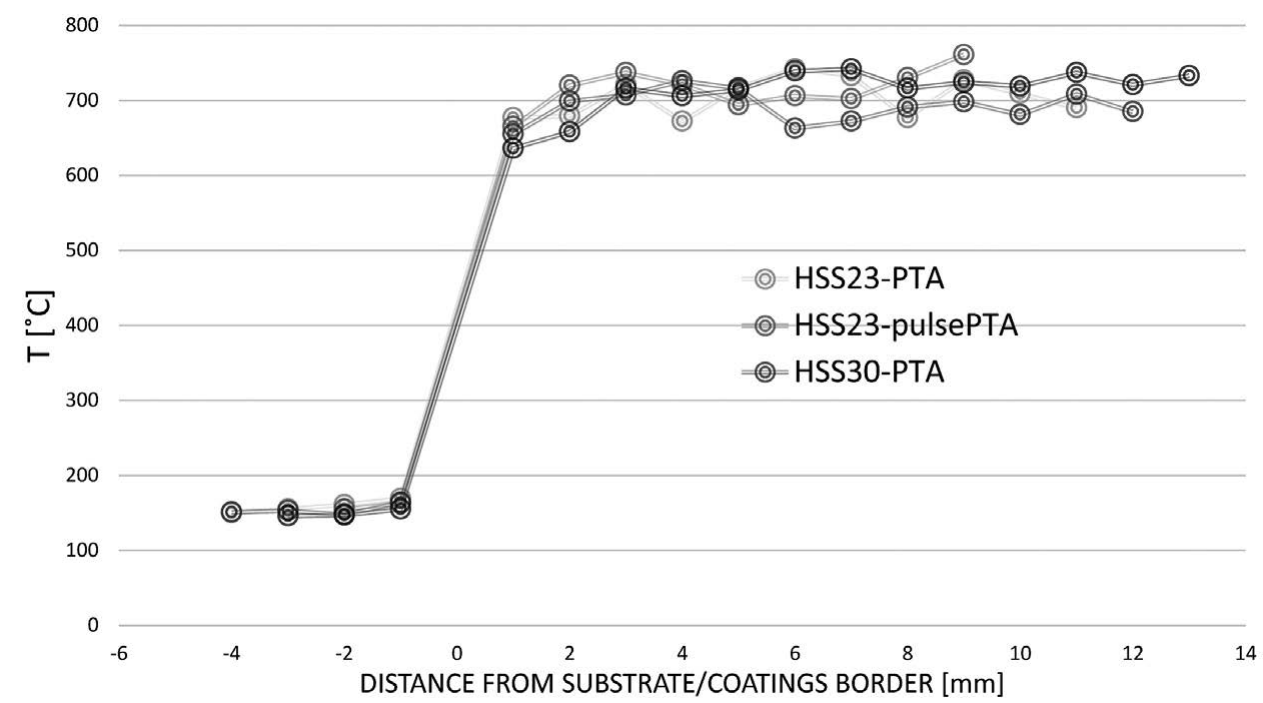

Fig. 5. Hardness HV05 of PTA, resp. pulse PTA deposits

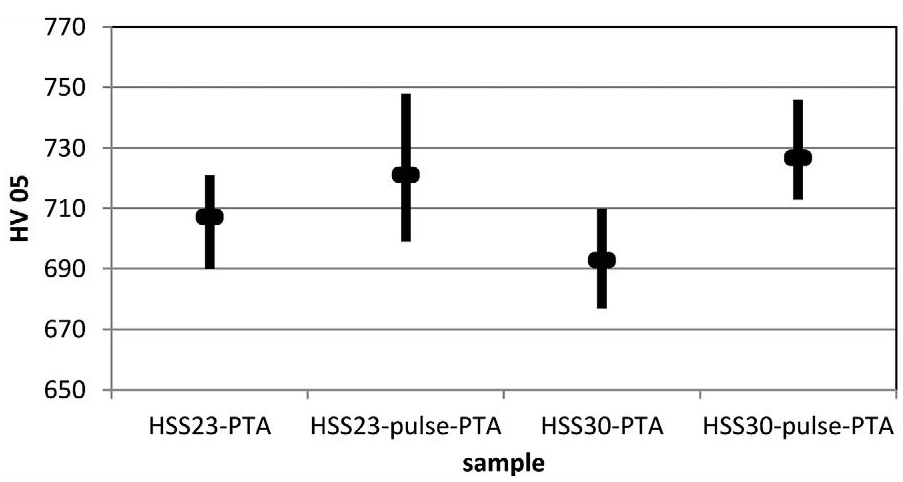

Fig. 6. Hardness HV05 $1 \mathrm{~mm}$ under free surface. Average, maximum, minimum values 
the cladding matrix. According to CCT-graph (continuous cooling) of the studied alloys the hardness of deposits should be higher than measured. The reason is that the plasma torch waving causes local tempering of deposit by a number of heating/ cooling cycles after rapid crystallization.

\section{CONCLUSIONS}

Plasma deposition of high speed steel type HSS 23, resp. HSS 30 is a promising possibility to use PTA, resp. pulse PTA as an effective way to make wear-resistant coatings and/or 3D shaped deposits. Thanks to high interpass temperature, the grain size is uniformly distributed and hardness of deposit also does not show any irregularities. Pulse PTA showed better results in hardness of deposits of both HSS 23 and HSS 30 high speed steels. The PTA deposit of HSS 23 resp. HSS 30 can be used with or without following heat treatment. PTA welding overlay of HSS is another method of fabrication bulk hard wearresistant and non-porous surface or 3D deposits, except the Ospray method, casting and PM.

\section{Acknowledgements}

Research was supported by institutional support of CTU in Praha from Ministry of Education Youth and Sports in frame of project No. 2.

\section{REFERENCES}

1. Hou Q.Y., Gao J.S., Zhou F.: Microstructure and wear characteristics of cobalt-based alloy deposited by plasma transferred arc weld surfacing. Surface and Coatings Technology, 194(2-3), 2005, 238-243.

2. D’Oliveira A.S.C., Paredes R.S.C., Santos R.L.C., Pulsed current plasma transferred arc hardfacing. Journal of Materials Processing Technology, 171(2), 2006, 167-174.

3. Rohan P., Kramár T., Panáček T.: Plasma hardfacing diagnostics (in Czech). In: Koukal J. (Ed.) Proceedings „New Materials, Technologies and Equipment for Welding“, CWS ANB, TU in Ostrava 2015.

4. Balamurugan S., Murugan N.: Simulation of Plasma Transferred ARC (PTA) Hardfaced on Structural Steel with Titanium Carbide. Journal of Engineering, Computers \& Applied Sciences, 2(4), 2013.

5. Díaz V., Dutra J.C., D’Oliveira A.S.C.: Hardfacing by plasma transferred arc process. In: W. Sudnik (Ed.), InTech, Available from: http://www.intechopen.com/books/arc-welding/hardfacing-by-plasma-transferred-arc-process
6. Bayer A.M. and Becherer B.A., High Speed Tool Steels: Teledyne Vasco, ASM Handbook, Vol. 16: Machining ASM Handbook Committee, 51-59.

7. Alloying elements and their influence on properties of steel, Satyedra. Web: posted on Apr. 20, 2013 in Ispat digest, http://ispatguru.com/alloying-elements-and-their-influence-on-properties-of-steel/

8. Sourmail T.: Near equiatomic FeCo alloys: constitution, mechanical and magnetic properties. Web: http://thomas-sourmail.net/papers_html/FeCo_review/index.html, 2005

9. Madej M. 2012. Tungsten carbide as an addition to high speed steel based composites. Tungsten Carbide - Processing and Applications. In: Kui Liu (Ed.), InTech, DOI: 10.5772/51243. Available: http://www. intechopen.com/books/tungsten-carbide-processing-and-applications/tungsten-carbide-as-an-addition-to-high-speed-steel-based-composites

10. Wang H., Hou L, Zhang J., Lu L., Cui H., Zhang J., The secondary precipitates of niobium-alloyed M3:2 high speed steel prepared by spray deposition, Materials Characterization, 106, 2015, 245-254.

11. Mesquita R.A. and Barbosa C.A., Sumar'e HSS produced through conventional casting, sprayforming and powder metallurgy. In: Proceedings $6^{\text {th }}$ International Tooling Conference, Villares Metals S. A., Sumar'e, Brazil 2010.

12. Torralba J.M. et al.: A review of high speed steels made by powder metallurgy methods. Powder Metallurgy Science and Technology, 4(3), 1993, 18-26, Metal Powder Report, 49(6), 1994, p. 45.

13. Wang S.-H., J.-Y. Chen, L. Xue, A study of the abrasive wear behaviour of laser-clad tool steel coatings. Surface and Coatings Technology, 200(11), 2006, 3446-3458.

14. Liu Z.H., Zhang D.Q., Chua C.K., Leong K.F.: Crystal structure analysis of M2 high speed steel parts produced by selective laser melting. Materials Characterization, 84, 2013, 72-80.

15. Sun G.F., Wang K., Zhou R., Feng A.X., Zhang W.: Effect of different heat-treatment temperatures on the laser cladded M3:2 high-speed steel, Materials \& Design, 65, 2015, 606-616.

16. Vitry V., Nardone S., Breyer J.-P., Sinnaeve M., Delaunois F.: Microstructure of two centrifugal cast high speed steels for hot strip mills applications. Materials \& Design, 34, 2012, 372-378.

17. Bourithis L., Papadimitriou G.D.: Synthesizing a class " $M$ " high speed steel on the surface of a plain steel using the plasma transferred arc (PTA) alloying technique: microstructure and wear properties. Materials Science and Engineering, A361, 2003, 165-172.

18. Chaus A.S., Domankova M.: Precipitation of secondary carbides in M2 high-speed steel modified with titanium diboride. Journal of Materials Engineering and Performance, 22(5), 2013, 1412-1420. 